\title{
Sinomenine Purification by Continuous Liquid-Liquid Extraction Process with Centrifugal Extractors
}

\author{
Zuren Peng1, Wanying Wang', Xianjun Long1, Ping Qiu1, Qiaoqiao Liu1, \\ Yuanxiang Yang1, Xuechun Yang1, Meili Wang', Songmao Yin' ${ }^{1}$, Xingchu Gong2* \\ ${ }^{1}$ Hunan Zhenqin Pharmaceutical Group Co., Ltd., Huaihua, China \\ ${ }^{2}$ Pharmaceutical Informatics Institute, College of Pharmaceutical Sciences, Zhejiang University, Hangzhou, China \\ Email: *gongxingchu@zju.edu.cn
}

How to cite this paper: Peng, Z.R., Wang, W.Y., Long, X.J., Qiu, P., Liu, Q.Q., Yang, Y.X., Yang, X.C., Wang, M.L., Yin, S.M. and Gong, X.C. (2020) Sinomenine Purification by Continuous Liquid-Liquid Extraction Process with Centrifugal Extractors. Advances in Chemical Engineering and Science, 10, 171-180.

https://doi.org/10.4236/aces.2020.103012

Received: May 8, 2020

Accepted: June 14, 2020

Published: June 17, 2020

Copyright $\odot 2020$ by author(s) and Scientific Research Publishing Inc. This work is licensed under the Creative Commons Attribution International License (CC BY 4.0).

http://creativecommons.org/licenses/by/4.0/

\begin{abstract}
Continuous manufacturing is considered as one of the future trends of pharmaceutical engineering. In this work, continuous liquid-liquid extraction for sinomenine purification was realized with the usage of centrifugal extractors. Chloroform was used as the extractant because of the high distribution coefficient $(>100)$. Higher extraction ratio can be obtained when using the centrifugal extractor of Model CWL50-N. The extraction ratio of the second-stage extraction was higher than that of the first-stage extraction. The extraction ratio of the second-stage countercurrent extraction was higher than that of second-stage cross-flow extraction. When chloroform phase was recycled for liquid-liquid extraction, the extraction ratio was also higher than $95 \%$. This work can also be an example of continuous liquid-liquid extraction for the separation of other Chinese medicine components.
\end{abstract}

\section{Keywords}

Sinomenine, Continuous Manufacturing, Liquid-Liquid Extraction, Centrifugal Extractor

\section{Introduction}

Sinomenii Caulis is the dried cane of Sinomenium acutum (Thunb.) Rehd. et Wils. or Sinomenium acutum (Thunb.) Rehd.et Wils. var. cinereum Rehd. et Wils. [1]. As the main active ingredient of Sinomenii Caulis, sinomenine possesses the effects of removing wind and dehumidification, promoting blood circulation, diuresis and swelling [1]. Its boiling point is $513.6^{\circ} \mathrm{C}$ at $760 \mathrm{mmHg}$ and 
melting point is $161^{\circ} \mathrm{C}$. In industry, sinomenine hydrochloride is produced using the processes of percolation, filtration, $\mathrm{pH}$ adjustment, liquid-liquid extraction, concentration, crystallization and so on. Among them, liquid-liquid extraction is one of the critical processes, which can remarkably remove impurities and improve sinomenine purity. Sinomenine can be purified with salting-out extraction and reversed micellar extraction [2] [3]. However, liquid-liquid extraction is commonly carried out in a stirring tank in industry using chloroform as the extractant at present. The equipment is simple, but the liquid-liquid phase separation time is usually longer than $24 \mathrm{~h}$, resulting in low production efficiency.

Pharmaceutical continuous manufacturing refers to the process in which materials continuously enter the pharmaceutical system, and drug products continuously come out of it [4]. It is considered as one of the pharmaceutical emerging technologies [5]. Compared with batch manufacturing, continuous manufacturing can improve pharmaceutical manufacturing by using an integrated process with fewer steps and shorter processing times; enabling real-time product quality monitoring; and providing flexible operation to allow scale-up, and scale-down to accommodate changing supply demands [5] [6]. Adamo et al. developed a reconfigurable drug manufacturing platform, in which the continuous manufacturing technology was also used [7]. In 2019, the US Food and Drug Administration (FDA) issued the "Quality Considerations for Continuous Manufacturing Guidance for Industry (DRAFT GUIDANCE)”, which pointed out the considerations on process control strategy on continuous manufacturing of drugs [6].

At present, there are many published works on the continuous manufacturing of chemical drugs, involving different unit operations, such as synthesis [8], drying [9], and tableting [10]. Because of the lack of continuous manufacturing equipment and regulatory restrictions, there are relatively fewer reports on the continuous manufacturing of traditional Chinese medicines (TCMs). Due to the advantages of continuous manufacturing, new equipment suitable for TCM production was developed and investigated. The works on continuous countercurrent leaching of herbal materials [11] and continuous vacuum belt drying [12] can be found in literatures. Recently, the authors used a micromixer to continuously adding ethanol solution to TCM concentrate [13], which effectively intensified the mixing of ethanol precipitation process and reduced the coating loss [14]. However, there is no published work on the continuous liquid-liquid extraction process of TCMs.

In this work, chloroform was used as the extractant to purify Sinomenii Caulis extract. Centrifugal extractors were applied to realize a continuous liquid-liquid extraction process. Different models of centrifugal extractors were compared. The mode of liquid-liquid extraction was also optimized.

\section{Experimental Part}

\subsection{Material}

Sinomenii Caulis (lot number: Y-402006) was purchased from Hunan Huaihua 
changyuan Pharmaceutical Co., Ltd.. The standard substance of sinomenine (lot number: 110774-200507) was purchased from National Institutes for Food and Drug Control. Acetonitrile ( $(299.9 \%)$ was purchased from Tianjin Saifu Rui Technology Co., Ltd.. Chloroform (AR), hydrochloric acid (AR), and calcium hydroxide (AR) were purchased from Hunan Huihong Reagent Co., Ltd..

\subsection{Methods}

\subsubsection{Preparation of Feed Solution for Liquid-Liquid Extraction}

The medicinal herbs of Sinomenii Caulis were pulverized and percolated with $0.3 \mathrm{~mol} / \mathrm{L}$ hydrochloric acid solution. The percolating solution was collected. Calcium hydroxide was used to adjust the $\mathrm{pH}$ value of the percolating solution to 11 - 12. After filtration, the filtrate was collected. Hydrochloric acid was used to adjust the filtrate to a $\mathrm{pH}$ value of 8.5 to obtain the feed solution for liquid-liquid extraction.

\subsubsection{Batch Extraction}

$40 \mathrm{~mL}$ of the feed solution and $20 \mathrm{~mL}$ of chloroform were put into a separatory funnel. The separatory funnel was vigorously shaken to mix the two phases. After standing for the separation of two phases, the chloroform phase sample was collected. Then, $10 \mathrm{~mL}$ of chloroform was put into a separatory funnel. After full extraction, the chloroform phase sample and aqueous phase sample were collected. The content of sinomenine was determined by HPLC analysis.

\subsubsection{Continuous Extraction}

In this work, two models of centrifugal extractors (CWL50-M and CWL50-N, Zhengzhou TIEI Extraction Technology Co., Ltd) were used for continuous liquid-liquid extraction. The CWL50-M centrifugal extractor adopts the mixing method of blade mixing. The CWL50-N centrifugal extractor adopts the mixing method of annular gap mixing. The power consumption CWL50-N centrifugal extractor is relatively higher than that of CWL50-M centrifugal extractor. Based on the results of the pre-experiment, the following research conditions were determined.

\section{Single-stage continuous extraction}

The centrifugal extractor was used for the single-stage continuous liquid-liquid extraction. The schematic diagram was shown in Figure 1. During extraction, the motor stirring frequency was $48 \mathrm{~Hz}$ and the height of weir plate was $28 \mathrm{~mm}$. The flowrates of feed solution and chloroform were $80 \mathrm{~mL} / \mathrm{min}$ and $60 \mathrm{~mL} / \mathrm{min}$, respectively. After continuous extraction for $10 \mathrm{~min}$, samples of the extract and raffinate were taken for analysis.

\section{Two-stage cross-flow continuous extraction}

The centrifugal extractors were used for two-stage cross-flow continuous extraction. The schematic diagram was shown in Figure 2. During extraction, the motor stirring frequency was $48 \mathrm{~Hz}$, the height of first-stage weir plate was 28 $\mathrm{mm}$, and the height of second-stage weir plate was $28.5 \mathrm{~mm}$. The flowrate of feed 
solution was $80 \mathrm{~mL} / \mathrm{min}$. The flowrates of chloroform were $40 \mathrm{~mL} / \mathrm{min}$ in the first-stage centrifugal extraction, and $20 \mathrm{~mL} / \mathrm{min}$ in the second-stage centrifugal extraction, respectively. After 15 minutes of continuous extraction, samples of the extract and raffinate were taken for analysis.

\section{Two-stage countercurrent continuous extraction}

The centrifugal extractors were used for two-stage countercurrent continuous extraction. The schematic diagram was shown in Figure 3. During extraction, the motor stirring frequency was $48 \mathrm{~Hz}$, the height of first-grade weir plate was $28 \mathrm{~mm}$, and the height of second-grade weir plate was $28.5 \mathrm{~mm}$. The flowrates of feed solution and chloroform were $80 \mathrm{~mL} / \mathrm{min}$ and $60 \mathrm{~mL} / \mathrm{min}$, respectively. After continuous extraction for more than $10 \mathrm{~min}$, samples of the extract and raffinate were taken for analysis.

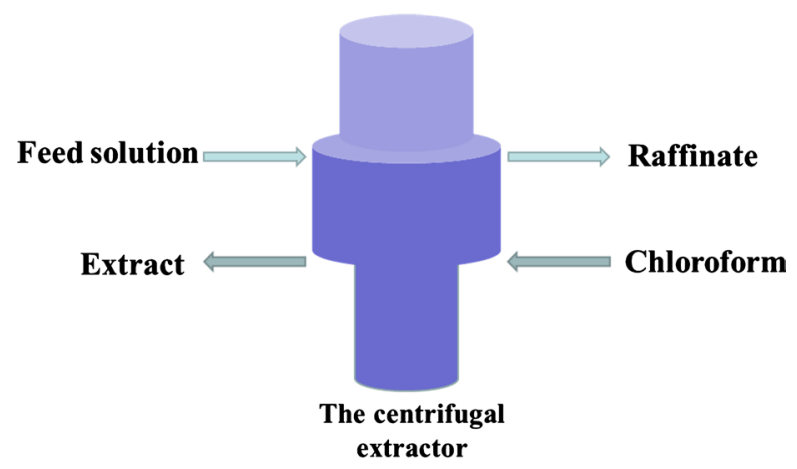

Figure 1. Schematic diagram of the single-stage continuous extraction.

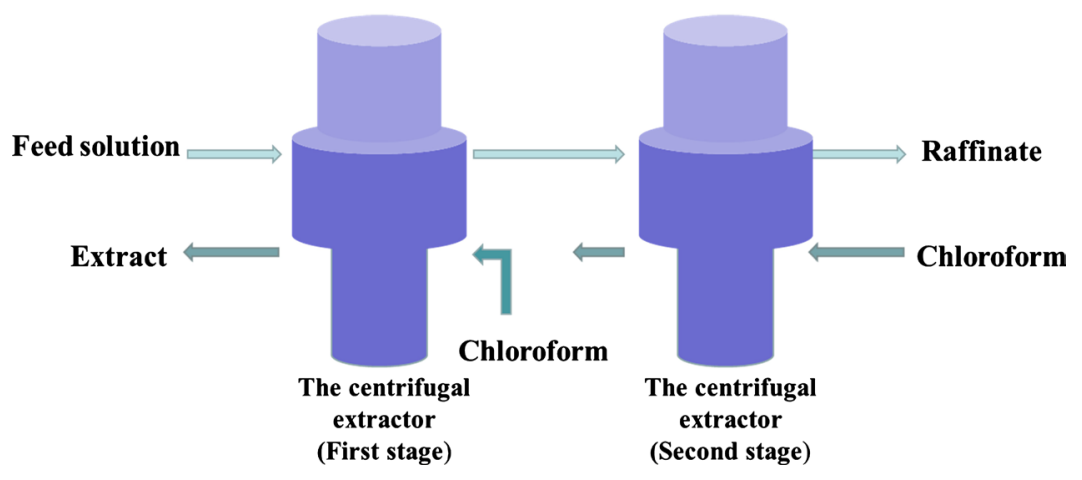

Figure 2. Schematic diagram of two-stage cross-flow continuous extraction.

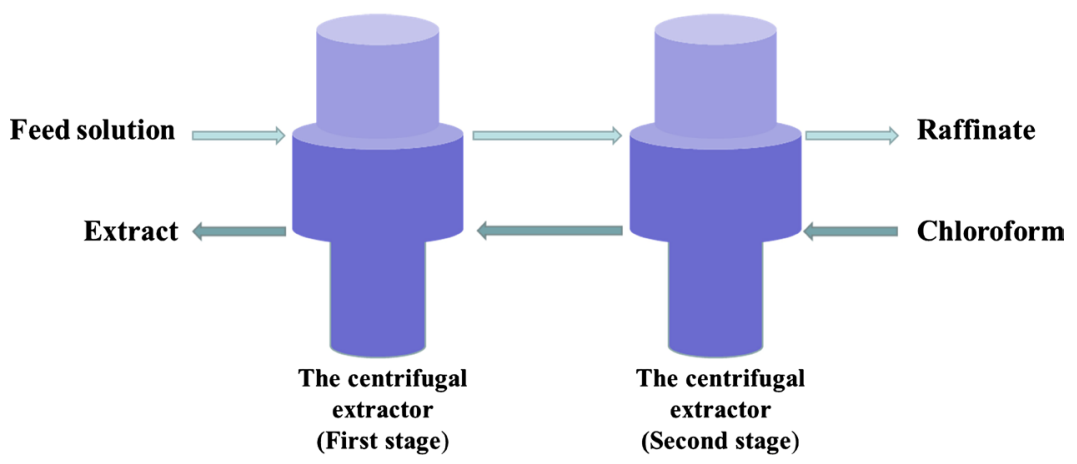

Figure 3. Schematic diagram of two-stage countercurrent continuous extraction. 


\section{Two-stage continuous countercurrent extraction with chloroform phase} recycled

The centrifugal extractors were used for continuous countercurrent extraction with two stages of chloroform circulation. The schematic diagram was shown in Figure 4. During extraction, the height of first-stage weir plate was $28 \mathrm{~mm}$, the height of second-stage weir plate was $28.5 \mathrm{~mm}$, and the motor stirring frequency was $48 \mathrm{~Hz}$. The flowrates of feed solution and chloroform phase were $80 \mathrm{~mL} / \mathrm{min}$ and $60 \mathrm{~mL} / \mathrm{min}$, respectively. At $5 \mathrm{~min}, 10 \mathrm{~min}, 15 \mathrm{~min}, 20 \mathrm{~min}, 30 \mathrm{~min}$, the samples of raffinate were taken. At $30 \mathrm{~min}$, the sample of chloroform phase was taken for analysis.

\subsubsection{Determination of Sinomenine Concentration}

The concentration of sinomenine was determined with a high-performance liquid chromatography (SPD-10A, Shimadzu Corporation). The column was Diamonsil C18 column $\left(250^{\star} 4.6 \mathrm{~mm}, 5 \mu \mathrm{m}\right)$. The mobile phase was $0.78 \%$ sodium dihydrogen phosphate solution-acetonitrile $(85: 15, \mathrm{v} / \mathrm{v})$. The detection wavelength was $265 \mathrm{~nm}$. The injection volume was $20 \mu \mathrm{L}$.

The standard substance of sinomenine was weighed precisely. Then 0.01 mol/L hydrochloric acid solution was added to prepare solution with a concentration of $100 \mu \mathrm{g} / \mathrm{mL}$. The standard substance solution was obtained after shaking.

Feed solution was sampled after filtration. $2 \mathrm{~mL}$ of feed solution was diluted in a $100 \mathrm{~mL}$ volumetric flask with $0.01 \mathrm{~mol} / \mathrm{L}$ hydrochloric acid solution. After dilution, the volumetric flask was shaken for few minutes to get a clear feed solution sample. Before sampling, the raffinate or extract solution was filtered with a filter paper. $2 \mathrm{~mL}$ of the raffinate or extract solution was dried on a water bath. After that, the dry matter was dissolved with $0.01 \mathrm{~mol} / \mathrm{L}$ hydrochloric acid solution, and diluted in a $100 \mathrm{~mL}$ volumetric flask before HPLC analysis.

Chromatograms are shown in Figure 5. By comparing Figure 5(b) and Figure 5(c), it can be concluded that many impurities were removed after liquid-liquid extraction. In Figure 5(d), the sinomenine peak area was very small, indicating that most sinomenine was extracted by the chloroform. By comparing Figure 5(b) and Figure 5(d), it is obvious that most of impurities remained in

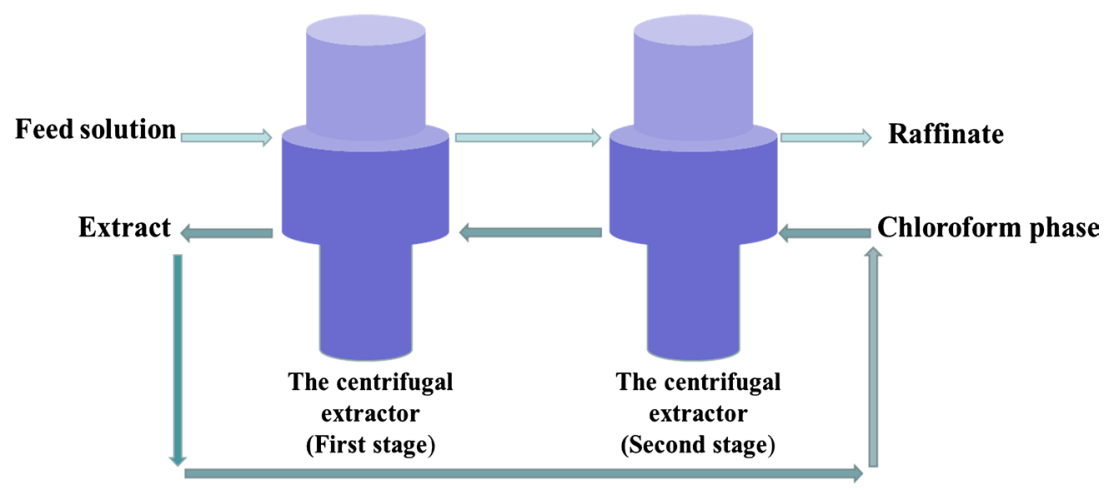

Figure 4. Schematic diagram of two-stage continuous countercurrent extraction for chloroform recycling. 


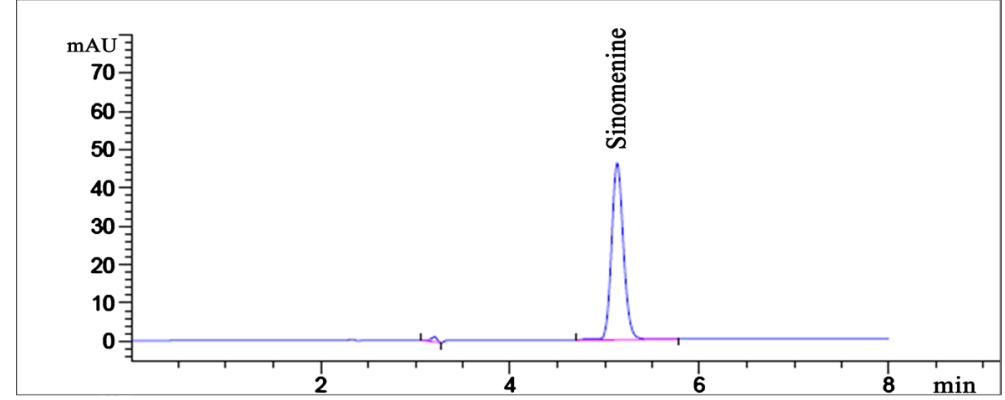

(a)

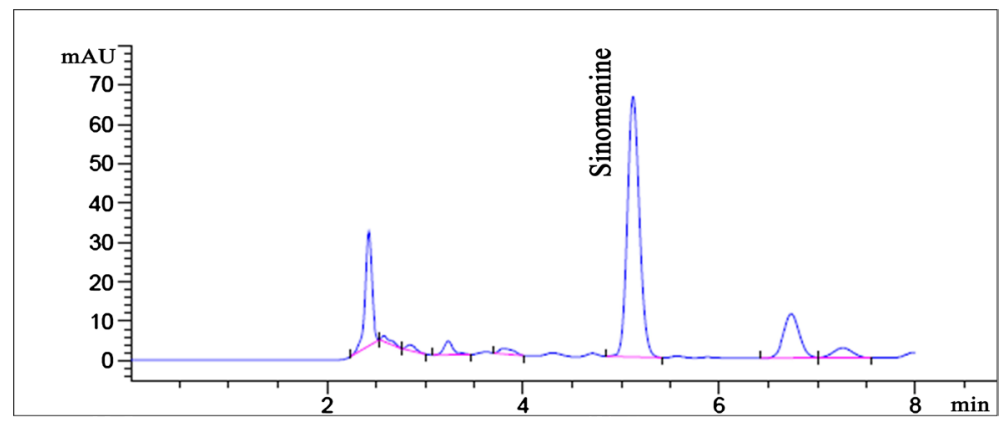

(b)

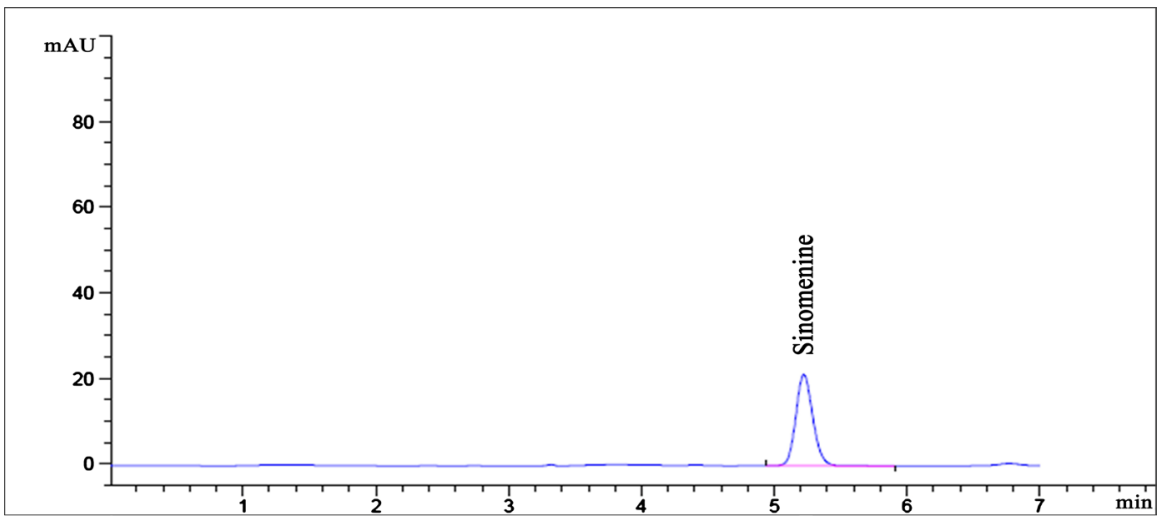

(c)

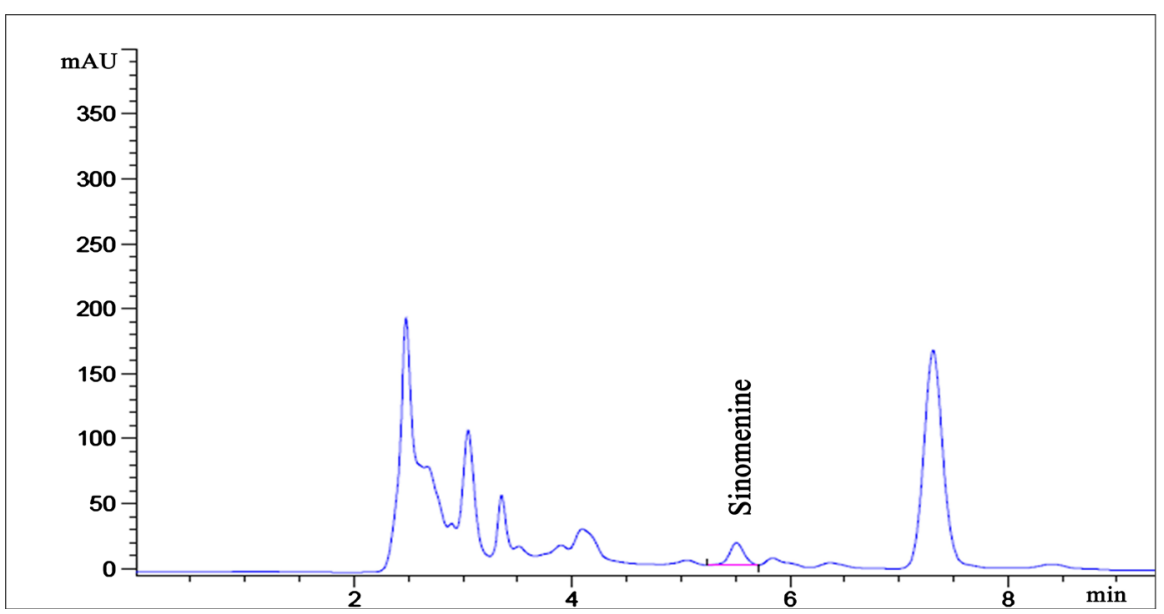

(d)

Figure 5. HPLC chromatograms of (a) Sinomenine standard substance solution, (b) Feed solution, (c) Extract, and (d) Raffinate. 
raffinate, indicating a good separation selectivity of liquid-liquid extraction.

\section{Results and Discussion}

\subsection{Distribution Coefficient of Sinomenine}

Equation (1) was the distribution coefficient of sinomenine.

$$
D=\frac{C_{\text {org }}}{C_{\text {aq }}}
$$

$D$-Distribution coefficient

C-Sinomenine concentration

org-Chloroform phase

aq-Aqueous phase

The liquid-liquid distribution coefficient values using chloroform as the extractant are shown in Table 1. Distribution coefficient values are very high $(>100)$, which indicates that chloroform can enrich sinomenine from low concentration aqueous solution.

\subsection{Comparison of Liquid-Liquid Extraction Mode and Centrifugal Extractors}

Different liquid-liquid extraction modes and different models of centrifugal extractors were used to extract sinomenine in the feed solution. Assuming that the volume of the aqueous phase did not change before and after liquid-liquid extraction, the extraction ratio was calculated with Equation (2).

$$
R=\left(1-\frac{C_{r}}{C_{f}}\right) \times 100 \%
$$

$$
\begin{aligned}
& R \text {-Extraction ratio } \\
& r \text {-Raffinate } \\
& f \text {-Feed solution }
\end{aligned}
$$

The extraction ratio values are listed in Table 2.

In Table 2, from the comparison of E2 and E3, E4 and E5, it can be concluded that CWL50-N centrifugal extractor performed higher extraction efficiency. The reason may be that the power of CWL50-N centrifugal extractor was higher, and the performance of liquid-liquid two-phase mixing and phase separation was better. The advantage of the CWL50-M centrifugal extractor was energy saving. In Experiment E1, after two batch extraction, the extraction ratio was $99.5 \%$,

Table 1. Distribution coefficient.

\begin{tabular}{ccc}
\hline \multicolumn{2}{c}{ The concentration of sinomenine $(\mathrm{mg} / \mathrm{ml})$} & Distribution coefficient \\
\hline Chloroform phase & Aqueous phase & 118 \\
7.05 & 0.06 & 439 \\
30.71 & 0.07 & 168 \\
99.01 & 0.59 &
\end{tabular}


indicating that chloroform was a good extractant for sinomenine separation. The result of Experiment E5 was the closest to that of E1, which also confirms that the CWL50-N centrifugal extractor has higher extraction efficiency than that of CWL50-M.

Comparing the results of Experiments E2, E4, and E6, it can be seen that the performance of the second-stage extraction was better than that of the single-stage extraction. Compared E4 with E6, the extraction ratio of second-stage countercurrent extraction was higher than that of second-stage cross-flow extraction. At the same extraction ratio, the two-stage countercurrent extraction will consume less pipeline and extractant amount. Accordingly, two-stage countercurrent extraction is favored.

The liquid-liquid extraction mode of the two-stage countercurrent extraction with chloroform phase recycled was also investigated. The results are shown in Table 3. When the recycling time of chloroform phase was from $5 \mathrm{~min}$ to 30 min, the concentration of sinomenine in the raffinate remains unchanged, which was between $0.15-0.18 \mathrm{mg} / \mathrm{mL}$. The extraction ratio values were all higher than $95 \%$. It means that although chloroform phase was recycled, it can still achieve a high extraction ratio due to the large distribution coefficient of sinomenine.

Table 2. The liquid-liquid extraction results under different experimental conditions.

\begin{tabular}{|c|c|c|c|c|c|c|c|}
\hline \multirow{2}{*}{$\begin{array}{l}\text { Experiment } \\
\text { number }\end{array}$} & \multirow[b]{2}{*}{ Extraction mode } & \multirow{2}{*}{$\begin{array}{l}\text { Model of } \\
\text { centrifugal } \\
\text { extractor }\end{array}$} & \multicolumn{4}{|c|}{ The concentration of sinomenine $(\mathrm{mg} / \mathrm{mL})$} & \multirow[b]{2}{*}{$\begin{array}{l}\text { Extraction } \\
\text { ratio (\%) }\end{array}$} \\
\hline & & & $\begin{array}{l}\text { Extract solution } \\
\quad \text { (first stage) }\end{array}$ & $\begin{array}{l}\text { Raffinate } \\
\text { (first stage) }\end{array}$ & $\begin{array}{c}\text { Extract solution } \\
\text { (second stage) }\end{array}$ & $\begin{array}{c}\text { Raffinate } \\
\text { (second stage) }\end{array}$ & \\
\hline E1 & Batch extraction & l & 7.05 & 0.06 & 0.70 & 0.02 & 99.5 \\
\hline E2 & Single-stage continuous extraction & CWL50-M & 4.42 & 0.79 & l & l & 80.2 \\
\hline E3 & Single-stage continuous extraction & CWL50-N & 5.16 & 0.20 & l & l & 95.0 \\
\hline $\mathrm{E} 4$ & $\begin{array}{l}\text { Two-stage cross-flow continuous } \\
\text { extraction }\end{array}$ & CWL50-M & 5.97 & l & 2.67 & 0.44 & 89.0 \\
\hline E5 & $\begin{array}{c}\text { Two-stage cross-flow continuous } \\
\text { extraction }\end{array}$ & CWL50-N & 7.66 & l & 3.60 & 0.04 & 99.0 \\
\hline E6 & $\begin{array}{l}\text { Two-stage countercurrent } \\
\text { continuous extraction }\end{array}$ & CWL50-M & l & I & 5.14 & 0.18 & 95.5 \\
\hline
\end{tabular}

Table 3. Extraction effect of sinomenine under different cycle times.

\begin{tabular}{cccc}
\hline \multirow{2}{*}{ Circulation time $(\mathrm{min})$} & \multicolumn{2}{c}{ The concentration of sinomenine $(\mathrm{mg} / \mathrm{mL})$} & \multirow{2}{*}{ Extraction ratio (\%) } \\
\cline { 2 - 3 } & Extract & Raffinate & \\
\hline 5 & $/$ & 0.17 & 95.8 \\
10 & $/$ & 0.16 & 96.0 \\
15 & $/$ & 0.18 & 95.5 \\
20 & $/$ & 0.16 & 96.0 \\
30 & 15.32 & 0.15 & 96.2 \\
\hline
\end{tabular}




\section{Conclusion}

In this work, chloroform was found to be an extractant with large distribution coefficient for sinomenine extraction. Continuous liquid-liquid extraction can be realized when using a centrifugal extractor. The result of two-stage extraction was better than that of single-stage extraction. The efficiency of two-stage countercurrent extraction was higher than that of two-stage cross-flow extraction. The extraction ratio of CWL50-N centrifugal extractor was higher under similar extraction conditions. Continuous liquid-liquid extraction process is promising to be a critical part of continuous production of sinomenine hydrochloride. The results in this work can also be a reference for the continuous extraction process of other Chinese medicine products.

\section{Conflicts of Interest}

The authors declare no conflicts of interest regarding the publication of this paper.

\section{References}

[1] Chinese Pharmacopoeia Commission (2015) Pharmacopoeia of the People's Republic of China (Part I). 2015 Edition, China Pharmaceutical Science and Technology Press, Beijing.

[2] Li, F.F., Li, Q., Wu, S.G., Sun, D.Y. and Tan, Z.J. (2017) Salting-Out Extraction of Sinomenine from Sinomenium Acutum by an Alcohol/Salt Aqueous Two-Phase System Using Ionic Liquids as Additives. Journal of Chemical Technology and Biotechnology, 93, 1925-1930. https://doi.org/10.1002/jctb.5318

[3] Li, Q., Wu, S.G., Wang, C.Y., Yi, Y.J., Zhou, W.L., Wang, H.Y., Li, F.F. and Tan, Z.J. (2017) Ultrasonic-Assisted Extraction of Sinomenine from Sinomenium Acutum Using Magnetic Ionic Liquids Coupled with Further Purification by Reversed Micellar Extraction. Process Biochemistry, 58, 282-288.

https://doi.org/10.1016/j.procbio.2017.04.030

[4] Yu, L.X. and Kopcha, M. (2017) The Future of Pharmaceutical Quality and the Path to Get There. International Journal of Pharmaceutics, 528, 354-359. https://doi.org/10.1016/j.ijpharm.2017.06.039

[5] Lee, S.L., O'connor, T.F., Yang, X., Cruz, C.N., Chatterjee, S., Madurawe, R.D., Moore, C.M.V., Yu, L.X. and Woodcock, J. (2015) Modernizing Pharmaceutical Manufacturing: From Batch to Continuous Production. Journal of Pharmaceutical Innovation, 10, 191-199. https://doi.org/10.1007/s12247-015-9215-8

[6] Food and Drug Administration (2019) Quality Considerations for Continuous Manufacturing-Guidance for Industry-Draft Guidance.

https://www.fda.gov/regulatory-information/search-fda-guidance-documents/qualit y-considerations-continuous-manufacturing

[7] Adamo, A., Beingessner, R.L., Behnam, M., Chen, J., Jamison, T.F., Jensen, K.F., Monbaliu, J.-C.M., Myerson, A.S., Revalor, E.M., Snead, D.R., Stelzer, T., Weeranoppanant, N., Wong, S.Y. and Zhang, P. (2016) On-Demand Continuous-Flow Production of Pharmaceuticals in a Compact, Reconfigurable System. Science, 352, 61-67. https://doi.org/10.1126/science.aaf1337

[8] Diab, S., Mcquade, D.T., Gupton, B.F. and Gerogiorgis, D.I. (2019) Process Design 
and Optimization for the Continuous Manufacturing of Nevirapine, an Active Pharmaceutical Ingredient for HIV Treatment. Organic Process Research \& Development, 23, 320-333. https://doi.org/10.1021/acs.oprd.8b00381

[9] Domokos, A., Nagy, B., Gyürkés, M., Farkas, A., Tacsi, K., Pataki, H., Liu, Y. C., Balogh, A., Firth, P. and Szilágyi, B. (2020) End-to-End Continuous Manufacturing of Conventional Compressed Tablets: from Flow Synthesis to Tableting through Integrated Crystallization and Filtration. International Journal of Pharmaceutics, 2020, Article ID: 119297. https://doi.org/10.1016/j.ijpharm.2020.119297

[10] Puri, V., Brancazio, D., Desai, P.M., Jensen, K.D., Chun, J.-H., Myerson, A.S. and Trout, B.L. (2017) Development of Maltodextrin-Based Immediate-Release Tablets Using an Integrated Twin-Screw Hot-Melt Extrusion and Injection-Molding Continuous Manufacturing Process. Journal of Pharmaceutical Sciences, 106, 3328-3336. https://doi.org/10.1016/j.xphs.2017.06.020

[11] Rao, R.N., Talluri, M.K., Krishna, T.M. and Ravindranath, K. (2008) Continuous Counter Current Extraction, Isolation and Determination of Solanesol in Nicotiana Tobacum L. by Non-aqueous Reversed Phase High Performance Liquid Chromatography. Journal of Pharmaceutical and Biomedical Analysis, 46, 310-315. https://doi.org/10.1016/j.jpba.2007.10.014

[12] Liu, X., Qiu, Z., Wang, L. and Chen, Y. (2011) Quality Evaluation of Panax Notoginseng Extract Dried by Different Drying Methods. Food and Bioproducts Processing, 89, 10-14. https://doi.org/10.1016/j.fbp.2010.03.008

[13] Gong, X., Shen, J. and Qu, H. (2016) Application of Continuous Mixing Technology in Ethanol Precipitation Process of Salvia Miltiorrhiza by Using Micromixer. China Journal of Chinese Materia Medica, 41, 4356-4361. https://doi.org/10.4268/cjcmm20162311

[14] Pan, J., Shao, J., Qu, H. and Gong, X. (2020) Ethanol Precipitation of Codonopsis Radix Concentrate with a Membrane Dispersion Micromixer. Journal of Cleaner Production, 251, Article ID: 119633. https://doi.org/10.1016/j.jclepro.2019.119633 